\title{
PENGELOLAAN PERIKANAN WADUK SAGULING, CIRATA, DAN IR. H. DJUANDA, JAWA BARAT
}

\author{
Didik Wahju Hendro Tjahjo') dan Ali Suman' ${ }^{2)}$ \\ 1) Peneliti pada Loka Riset Pemacuan Stok Ikan-Jatiluhur, Purwakarta \\ 2) Peneliti pada Balai Riset Perikanan Perairan Umum-Mariana, Palembang \\ Teregistrasi I tanggal: 11 April 2008; Diterima setelah perbaikan tanggal: 18 April 2008; \\ Disetujui terbit tanggal: 25 April 2008
}

\section{ABSTRAK}

Tulisan ini bertujuan untuk mengamati pengelolaan dan pemanfaatan sumber daya perikanan di waduk kaskade (Saguling, Cirata, dan Djuanda). Hasil analisis menunjukkan bahwa pengelolaan dan pemanfaatan sumber daya perikanan di perairan waduk ini sudah berada dalam tahapan yang melebihi daya dukung lingkungan. Agar kelestarian sumber daya perikanan tetap terjaga secara berkesinambungan, maka perlu dilakukan perbaikan lingkungan waduk, pengaturan jumlah karamba jaring apung yang dioperasikan dan pengaturan jenis ikan budi daya.

\section{KATAKUNCl: pengelolaan perikanan, waduk kaskade, Jawa Barat}

ABSTRACT: Fishery management in Saguling, Cirata, and Ir. H. Djuanda reservoirs, West Java. By: Didiek Wahju Hendro Tjahjo and Ali Suman

The objective of this paper is to analysis management and exploitation of cascade reservoirs, west Java. The result showed that management and exploitation of fishery resources in this waters was over carryng capacity of reservoir environment. The strategy of sustainable exploitation of fishery resources in this reservoirs e.g. rehabilitation of reservoir environment, restriction fish cage, and regulation of fish culture species in reservoir.

\section{KEYWORDS: fishery management, cascade reservoirs, West Java}

\section{PENDAHULUAN}

Perairan waduk kaskade di Sungai Citarum terdiri atas Waduk Saguling, Cirata, dan Ir. H. Djuanda. Keadaan ketiga perairan waduk tersebut cukup potensial dan sangat mendukung kehidupan penduduk di sekitarnya melalui kegiatan penangkapan dan budi daya ikan. Prospek pemanfaatan waduk dalam jangka panjang tidak begitu menggembirakan, karena berbagai tekanan lingkungan terhadap kelestarian sumber daya perairan. Banyak limbah industri, perkotaan, pertanian, dan perikanan yang masuk ke perairan menyebabkan degradasi kualitas lingkungan, dan selanjutnya menimbulkan tingginya laju kematian bagi sumber daya ikan. Di sisi lain, waduk kaskade memiliki dinamika yang khas, yaitu kualitas perairan di sebelah hilir sangat dipengaruhi oleh pengelolaan lingkungan perairan waduk di bagian hulunya.

Masalah utama dalam pengelolaan sumber daya waduk kaskade di sepanjang aliran Sungai Citarum adalah masalah lingkungan, baik kuantitas maupun kualitasnya yang timbul akibat interaksi antara aktivitas ekonomi dan kelestarian sumber daya perairan. Jumlah dan intensitas eksploitasi sumber daya perairan 
yang semakin meningkat tersebut berdampak terhadap meningkatnya degradasi kualitas lingkungan. Bentuk degradasi kualitas lingkungan tersebut antara lain pencemaran, eutrofikasi, penurunan keanekaragaman hayati, pendangkalan (sedimentasi), penurunan produksi, dan lain-lain.

\section{KEADAAN UMUM}

Waduk kaskade di Sungai Citarum dimulai dengan pembangunan Waduk Ir. $\mathrm{H}$. Djuanda pada tahun 1967. Waduk ini terletak pada ketinggian $116 \mathrm{~m}$ diatas permukaan laut (dpl) dengan luas 8.300 ha, kedalaman maksimum $95 \mathrm{~m}$, kedalaman rata-rata $36,4 \mathrm{~m}$ dan pengembangan garis pantai $5,96 \mathrm{~m}$ (Tjahjo, 1986). Selanjutnya, dibangun Waduk Saguling pada tahun 1985 di bagian hulu Sungai Citarum pada ketinggian $645 \mathrm{~m} \mathrm{dpl}$ dengan luas 5.600 ha, kedalaman rata-rata $17,5 \mathrm{~m}$ dan panjang garis pantai $473 \mathrm{~km}$. Terakhir pada tahun 1988 dibangun Waduk Cirata, waduk ini terletak di antara Waduk Saguling dan Waduk Ir. H. Djuanda. Waduk Cirata dibangun pada ketinggian $221 \mathrm{~m} \mathrm{dpl}$ dengan luas maksimum 6.200 ha, rata-rata kedalaman 34,9 m dan panjang garis pantai 181 km (Gambar 1).

Waduk Ir. H. Djuanda merupakan salah satu waduk serba guna, di mana fungsi utamanya adalah pembangkit listrik tenaga air, bahan baku air minum, irigasi, dan pencegah banjir. Sedangkan Waduk Saguling dan Cirata mempunyai fungsi utama sebagai pembangkit listrik tenaga air. Dalam perkembangannya, ketiga waduk kaskade tersebut digunakan juga untuk kegiatan tambahan, seperti perikanan, transportasi, dan pariwisata.

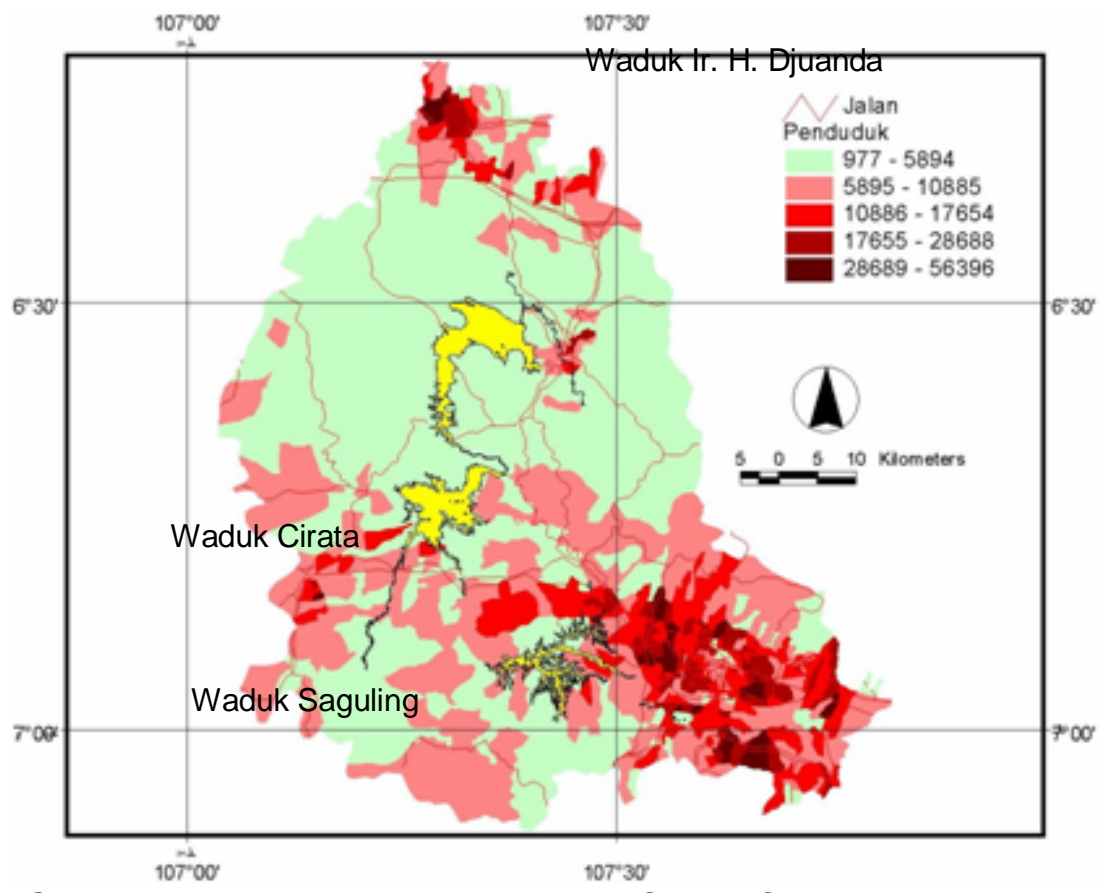

Gambar 1. Peta waduk kaskade di Sungai Citarum, Jawa Barat.

Figure 1. Map of cascade manmade lake in Citarum River, West Java. 


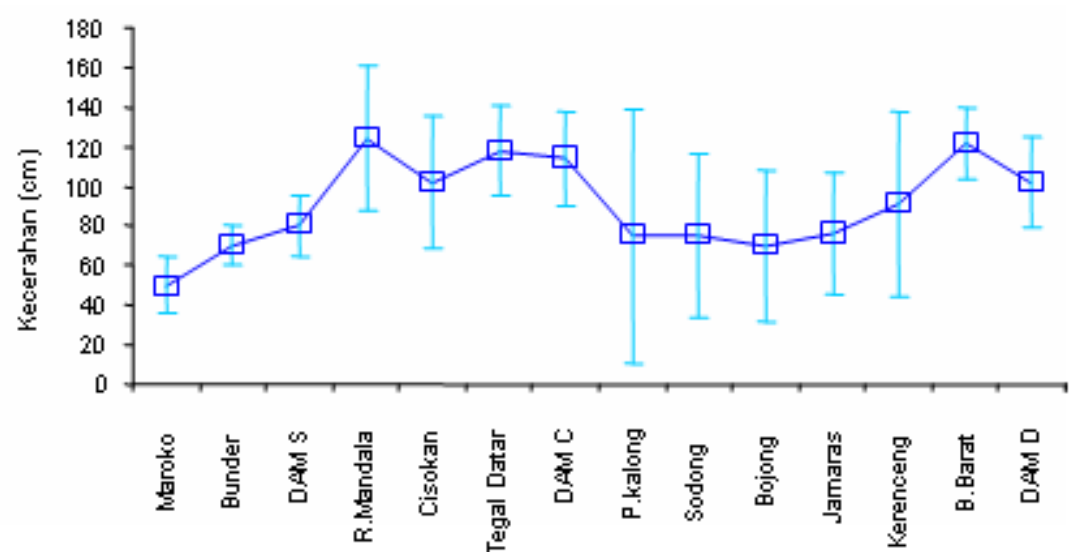

Gambar 2. Rata-rata kecerahan dan simpangan baku selama tahun 2006 menurut stasiun pengamatan alur Sungai Citarum di di Waduk Saguling, Cirata, dan Ir. H. Djuanda.

Figure 2. Mean transparancy value and standard deviation during 2006 according to observation station along channel of Citarum River in Saguling, Cirata, and Ir. H. Djuanda respectively.

\section{KERAGAAN KUALITAS PERAIRAN}

Waduk Saguling, Cirata, dan Ir. H. Djuanda mempunyai kecerahan $10-180 \mathrm{~cm}$. Inlet Sungai Citarum di Waduk Saguling (Stasiun Maroko) mempunyai kecerahan yang rendah, tetapi secara bertahap ke arah daerah air minum Saguling, kecerahan meningkat. Di Waduk Cirata kecerahan relatif paling tinggi dan sama antar stasiun pengamatan. Sedangkan di Waduk Ir. $\mathrm{H}$. Djuanda, di daerah inlet mempunyai kecerahan yang rendah, tetapi secara bertahap ke arah daerah air minum kecerahan meningkat. Daerah inlet Sungai Citarum, kecerahan sangat berfluktuasi. Hal tersebut, menunjukkan kecerahan di daerah tersebut sangat tergantung dari kualitas air yang dikeluarkan oleh Waduk Cirata. Rendah kecerahan di daerah ini disebabkan oleh bahan organik dan partikel tanah yang dibawa dari Waduk Cirata (Gambar 2). Hal tersebut, akan berdampak terhadap penguraian bahan organik menjadi bahan anorganik, seperti N-NH ${ }_{4}, \mathrm{~N}-\mathrm{NH}_{3}, \mathrm{~N}-\mathrm{NO}_{3}, \mathrm{~N}$ $\mathrm{NO}_{2}, \mathrm{P}_{-} \mathrm{PO}_{4}$, dan $\mathrm{H}_{2} \mathrm{~S}$.
Oksigen terlarut merupakan parameter kualitas air yang penting untuk menentukan kualitas air. Konsentrasi oksigen terlarut di permukaan berkisar 1,20-6,73 mg per L, di kedalaman $2 \mathrm{~m}$ berkisar 1,30-5,68 mg per $L$ dan di dasar perairan berkisar 0,52-4,43 mg per L (Gambar 3). Hasil pengamatan tersebut secara umum lebih rendah dibandingkan pengamatan kualitas air di Waduk Ir. H. Djuanda pada tahun 1983 (Nastiti \& Hardjamulia, 1986; Nastiti \& Hardjamulia, 1986a), tahun 1990 (Nastiti \& Purnomo, 1991), di Waduk Cirata pada tahun 1988-1989 (Umar, 1991), dan di Waduk Saguling pada tahun 1988-1989 (Nastiti et al., 1992).

Gambar 3 menunjukkan bahwa stasiun inlet Sungai Citarum di Waduk Saguling (Stasiun Maroko) mempunyai konsentrasi oksigen terlarut yang tinggi. Konsentrasi oksigen tersebut menunjukkan penurunan terus sampai di bagian inlet Waduk Ir. $\mathrm{H}$. Djuanda (Stasiun Parung Kalong-Sodong), dan selanjutnya konsentrasi oksigen terlarut secara bertahap terus meningkat sampai 


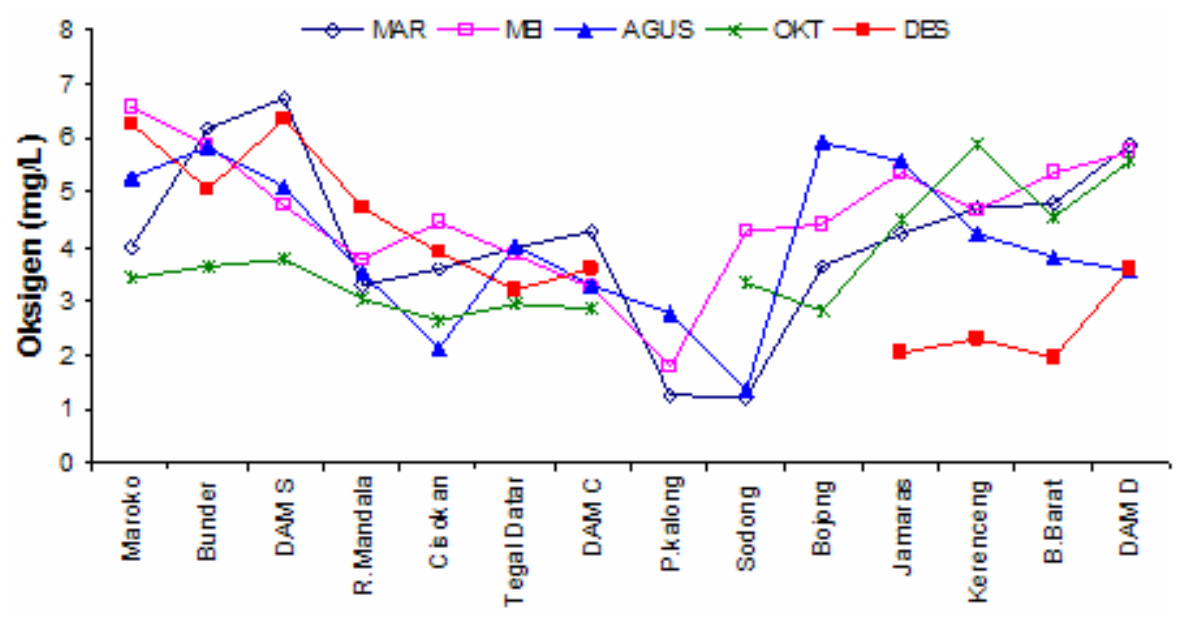

Gambar 3. Rata-rata oksigen terlarut pada kedalaman permukaan perairan menurut stasiun dan bulan pengamatan pada alur Sungai Citarum di Waduk Saguling, Cirata, dan Ir. H. Djuanda.

Figure 3. Mean value of dissoleved oxygen at different depth according to observation station and month, along channel of Citarum River in Saguling, Cirata, and Ir. H.Djuanda respectively.

daerah air minum Ir. H. Djuanda. Penurunan konsentrasi oksigen terlarut dari inlet Waduk Saguling, hingga inlet Waduk Ir. H. Djuanda diduga disebabkan bahan organik semakin meningkat dan kondisi ini membutuhkan oksigen yang tinggi untuk menguraikannya.

Fenomena tersebut diperkuat oleh distribusi vertikal oksigen terlarut di ketiga waduk tersebut (Gambar 4). Secara umum, gambar tersebut menunjukkan bahwa kandungan oksigen terlarut tertinggi di Waduk Ir. H. Djuanda dan terendah di Waduk Cirata. Berdasarkan hubungan tingkat kejenuhan oksigen dengan altitude oksigen terlarut, nilai tertinggi adalah di Waduk Saguling dan terendah di Waduk Ir. $\mathrm{H}$. Djuanda. Tetapi keadaan yang terjadi sebaliknya dan fenomena ini jelas menunjukkan bahwa kandungan bahan organik di Waduk Cirata jauh lebih tinggi dibandingkan di kedua waduk lainnya.
Konsentrasi $\mathrm{N}-\mathrm{NO}_{3}$ (nitrat) di permukaan berkisar tt-4,77 $\mathrm{mg}$ per $\mathrm{L}$, kedalaman $2 \mathrm{~m}$ berkisar $0,04-3,46 \mathrm{mg}$ per $\mathrm{L}$ dan dasar perairan berkisar tt-8,92 mg per L. Hasil pengamatan tersebut secara umum jauh lebih tinggi dibandingkan pengamatan kualitas air pada tahun 1983 (Nastiti \& Hardjamulia, 1986), dan tahun 1990 (Nastiti \& Purnomo, 1991), di Waduk Cirata pada tahun 1988-1989 (Umar, 1991), dan di Waduk Saguling pada tahun 19881989 (Nastiti et al., 1992). Salah satu sumber nitrat kemungkinan berasal dari dekomposisi bahan organik dari pengendapan sisa pakan dan feses ikan, baik bahan organik yang berasal dari karamba jaring apung di waduk itu sendiri maupun waduk yang ada di atasnya. Konsentrasi $\mathrm{N}-\mathrm{NO}_{3}$ yang tinggi dapat menstimulir pertumbuhan alga (algae blooming) di Waduk Ir. H. Djuanda. 


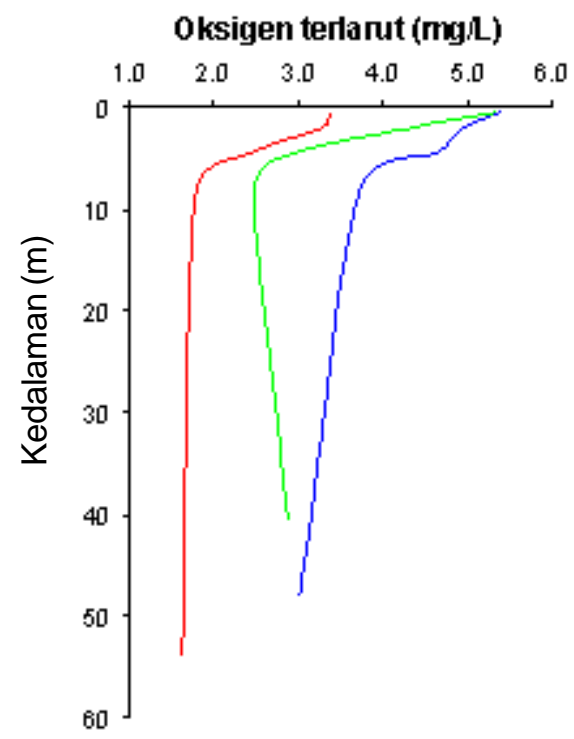

Gambar 4. Rata-rata bulanan distribusi vertikal oksigen terlarut di stasiun pengamatan daerah air minum Waduk Saguling (-), Cirata (-), dan Ir. H. Djuanda (-) pada tahun 2006.

Figure 4. Mean monthly value of vertical distribution of dissolved oxygen in observation station of dam Saguling (-), Cirata (-), and Ir. H. Djuanda (一) in 2006.

Konsentrasi $\mathrm{P}_{-} \mathrm{PO}_{4}$ permukaan berkisar $\mathrm{tt}-4,08 \mathrm{mg}$ per $\mathrm{L}$, kedalaman $2 \mathrm{~m}$ berkisar $0,01-2,94 \mathrm{mg}$ per $\mathrm{L}$ dan dasar perairan berkisar 0,03-7,15 $\mathrm{mg}$ per L. Hasil pengamatan tersebut secara umum jauh lebih tinggi dibandingkan pengamatan kualitas air di Waduk Ir. H. Djuanda pada tahun 1983 (Nastiti d\& Hardjamulia, 1986), dan tahun 1990 (Nastiti \& Purnomo, 1991), di Waduk Cirata pada tahun 1988-1989 (Umar, 1991), dan di Waduk Saguling pada tahun 1988-1989 (Nastiti et al., 1992). Hal ini menunjukkan bahwa tingkat pencemaran di ketiga waduk tersebut telah mencapai tingkat jauh lebih tinggi dibandingkan periode tahun 1980-1990.

Secara umum, konsentrasi $\mathrm{P}-\mathrm{PO}_{4}$ di Waduk Saguling lebih tinggi dibandingkan dua waduk lainnya. Tinggi konsentrasi $\mathrm{P}-\mathrm{PO}_{4}$ di Waduk Saguling mungkin disebabkan tingginya bahan organik yang berasal dari limbah perkotaan yang masuk ke waduk tersebut, sementara untuk Waduk Cirata dan Ir. H. Djuanda, sumber $\mathrm{P}_{-} \mathrm{PO}_{4}$ berasal perairan waduk di atasnya.

Kelimpahan fitoplankton sendiri di seluruh Waduk Saguling, Cirata, dan Ir. H. Djuanda berfluktuasi sedang, yaitu berkisar 100.000-400.000 ind. per L. Pada bulan Desember, kelimpahan fitoplankton tersebut paling rendah dan relatif stabil, kelimpahan rata-ratanya mencapai 94.254 ind. per L dengan simpangan baku 51.490 ind. per $\mathrm{L}$. Hal tersebut mungkin berhubungan dengan DMA dan debet air yang masuk ke masingmasing waduk paling rendah, sehingga jumlah nutrien yang masuk ke waduk pun paling rendah. Sebaliknya, rata-rata dan fluktuasi kelimpahan fitoplankton tertinggi pada bulan Maret yang mencapai 345.388 ind. per $L$ dengan simpangan baku 751.494 ind. per L, di mana DMA dan debet air yang 
masuk ke masing-masing waduk paling tinggi, sehingga pada bulan tersebut diduga jumlah nutrien yang masuk pun paling tinggi.

Berdasarkan rata-rata keanekaragaman seluruh stasiun pengamatan menunjukkan bahwa keanekaragaman berhubungan erat dengan volume air, kuantitas dan kesimbangan nutrien, serta intesitas matahari. Kualitas nutrien makin tinggi, keseimbangan $N: P$ seimbang, intensitas tinggi menunjukkan keanekaragaman fitoplankton yang semakin baik. Hal tersebut berarti bahwa pada bulan OktoberDesember dan Januari-Maret mempunyai peluang terjadinya blooming algae Cyanophyceae yang tinggi. Jika kondisi tersebut didukung dengan intensitas cahaya matahari yang sangat rendah dalam waktu yang lama (lebih dari 3 hari) dan ukuran ikan yang dibudidayakan dalam karamba jaring apung dalam ukuran individu yang besar (ukuran konsumsi), maka kondisi tersebut sangat mendukung terjadinya defisit oksigen terlarut, akibatnya terjadi kematian massal ikan.

\section{BUDI DAYA IKAN DALAM KARAMBA JARING APUNG}

Tujuan pengembangan budi daya ikan dalam karamba jaring apung di suatu badan air adalah untuk mengoptimalkan produksi ikan dan menjaga kelestarian lingkungan dan sumber daya perikanan, sehingga dapat dimanfaatkan secara optnum dan lestari oleh masyarakat sekitar badan air tersebut. Teknologi budidaya ikan dalam karamba jaring apung mampu memberikan produktivitas yang paling tinggi dibandingkan sistem budidaya ikan lain (Tabel 1). Jumlah unit karamba jaring apung di ketiga waduk tersebut telah berkembang pesat dan telah melampaui jumlah unit karamba jaring apung yang diizinkan, yaitu: 1. Waduk Saguling tahun 2005 jumlah karamba jaring apung yang beroperasi 7.272 unit.

2. Waduk Cirata tahun 2005 jumlah karamba jaring apung yang beroperasi 39.690 unit, sedangkan jumlah unit karamba jaring apung yang diizinkan berdasarkan pada Surat Keputusan Gubernur Jawa Barat No.41/2002 12.000 unit.

3. Waduk Ir. H. Djuanda tahun 2005 jumlah karamba jaring apung yang beroperasi 4.577 unit dan tahun 2006 jumlah karamba jaring apung yang beroperasi mencapai 15.000 unit, sedangkan jumlah yang diizinkan berdasarkan pada Surat Keputusan Bupati Purwakarta No.06/ 20002.100 unt.

Berdasarkan perhitungan daya dukung pengembangan budi daya ikan di karamba jaring apung pada tahun 1992 berdasarkan fosfat untuk Waduk Saguling, Cirata, dan Ir. H. Djuanda secara berturut-turut adalah 3.248, 2.904, dan 1.832 unit, di mana untuk Waduk Ir. H. Djuanda mengalami penurunan daya dukung yang cukup dratis. Tetapi jika dilihat hubungan antara jumlah unit karamba

Tabel 1. Produktivitas berbagai sistem perikanan budi daya

Table 1. Productivities at various culture fisheries systems

\begin{tabular}{lc}
\hline \multicolumn{1}{c}{$\begin{array}{c}\text { Sistem perikanan budi dayal } \\
\text { Aquaculture sistems }\end{array}$} & $\begin{array}{c}\text { Produktivitas (ton/ha/th)I } \\
\text { Productivities (ton/ha/year) }\end{array}$ \\
\hline Kolam air mengalir/Flowing water ponds & 3.497 \\
Kolam air deras/Running water ponds & 280.263 \\
Sawah/Paddy fields & 2.273 \\
Karamba jaring apung/Cages & 682.323 \\
\hline
\end{tabular}


jaring apung dengan produktivitas budidaya ikan dengan asumsi produktivitas karamba jaring apung yang layak dikembangkan 2 ton per unit per tahun, maka di masingmasing waduk tersebut dapat dikembangkan jumlah unit karamba jaring apung yang ideal untuk usaha di Waduk Saguling, Cirata, dan Ir. H. Djuanda secara berturut-turut 2.303, 4.549, dan 1.560 unit. Melihat data jumlah karamba jaring apung yang ada, maka telah terjadi kelebihan jumlah karamba jaring apung sekitar 4.024 unit untuk Waduk Saguling, 27.690 unit untuk Waduk Cirata, dan 12.900 unit untuk Waduk Ir. H. Djuanda. Dengan demikian, telah terjadi kelebihan di atas $100 \%$ dari daya dukung yang ada. Kondisi yang demikian akan memacu rutinitas terjadi pematian massal ikan, baik karena kekurangan oksigen maupun umbalan.

Dalam rangka mengurangi kematian masal pada budi daya ikan di karamba jaring apung dan meningkatkan kualitas air di waduk kaskade ini, maka perlu disusun langkah-langkah baik dalam jangka pendek maupun jangka panjang. Langkah-langkah jangka pendek antara lain:

1. Pengelolaan daerah aliran Sungai Citarum hendaknya dikelola oleh satu pengelola dalam rangka meningkatkan efektivitas dan efisiensi, koordinasi dan sinkronisasi dari perencanaan pelaksanaan evaluasi dan monitoring.

2. Pengurangan jumlah petak budidaya karamba jaring apung yaitu petak-petak karamba jaring apung yang belum dapat izin dan ilegal.

3. Pembenahan tata ruang pemanfaatan perairan waduk sesuai dengan daya dukung peraitran.

4. Tidak adanya izin baru ataupun izin penambahan petak budidaya.

Langkah-langkah jangka panjang meliputi:
1. Pembatasan jumlah maksimum petak untuk pengusaha.

2. Pengusaha budidaya ikan diutamakan penduduk sekitar waduk.

3. Peningkatan kualitas pakan dan benih.

4. Perbaikan kembali paket teknis budidaya ikan di karamba jaring apung yang disesuaikan perkembangan kondisi yang ada.

5. Penebaran jenis ikan yang mampu memanfaatkan plankton secara efektif dan bersifat pelagis.

6. Pengelolaan daerah aliran Sungai Citarum sebagai satu kesatuan ekosistem.

7. Penyusunan peraturan perundangundangan dalam pemanfaatan daerah aliran Sungai Citarum secara lestari dan berkesinambungan.

8. Peningkatan peran serta masyarakat dalam pengelolaan sumberdaya tersebut.

\section{REKOMENDASI KEBIJAKAN}

1. Berdasarkan pada trend kualitas lingkungan, kematian massal ikan tiap tahun akan terjadi pada bulan OktoberNopember di Waduk Saguling dan bulan Desember-Januari di Waduk Cirata dan Ir. H. Djuanda. Untuk mengantisipasi hal tersebut, maka kebijakan yang diambil adalah mengatur budidaya ikan dengan jenis yang tahan dalam kondisi oksigen yang minimum yaitu ikan nilem (Osteochillus haselti) dan patin (Pangasius djambal). Selain itu, apabila ingin mempertahankan jenis ikan budidaya yang sama dengan jenis pada periode normal, maka dilakukan pengurangan padat penebaran.

2. Jumlah karamba jaring apung sudah melampaui daya dukung perairan dan kondisi ini juga turut memicu kematian massal ikan setiap tahun. Untuk menuju 
pengelolaan perikanan yang rasional, maka disarankan untuk mengurangi jumlah karamba jaring apung sekitar 4.024 unit untuk Waduk Saguling, 27.690 unit untuk Waduk Cirata, dan 12.900 unit untuk Waduk Ir. H. Djuanda.

3. Dalam rangka mengurangi kematian masal pada budidaya ikan di karamba jaring apung dan meningkatkan kualitas air, maka dalam jangka panjang dapat dikurangi bahan-bahan organik yang masuk ke perairan waduk, baik Waduk Saguling Cirata maupun Ir. H. Djuanda. Untuk itu, maka pengelolaan daerah aliran Sungai Citarum hendaknya dikelola oleh satu pengelola dalam rangka meningkatkan efektivitas, efisiensi koordinasi, dan sinkronisasi dari perencanaan pelaksanaan evaluasi dan monitoring.

\section{DAFTAR PUSTAKA}

Nastiti, A. S., \& A. Hardjamulia. 1986a. Distribusi vertikal oksigen terlarut, suhu air, dan kandungan bahan organik di Waduk Jatiluhur, Jawa Barat. Buletin Penelitian Perikanan Darat. 5 (2): 8389.

Nastiti, A.S., \& K. Purnomo. 1991. Pengamatan kualitas air di sekitar lokasi budi daya ikan dalam karamba jarring apung di Teluk Ciganea, Waduk Jatiluhur. Buletin Penelitian Perikanan Darat. 10 (2): 9-22.
Nastiti, A. S,. \& A. Hardjamulia, 1986. Limnologi: Kondisi fisika dan kimia air di Waduk Jatiluhur, Jawa Barat dalam tahun 1983. Buletin Penelitian Perikanan Darat. 5 (1): 100-110.

Nastiti, A. S., S. Nuroniah, \& H. Satria, 1992. Penelitian pendahuluan dampak budi daya ikan dalam karamba jarring apung terhadap perairan Waduk Saguling. Buletin Penelitian Perikanan Darat. 11 (2): 8-19.

Tjahjo, D. W. H. 1986. Ciri-ciri morphologi Waduk Saguling dan beberapa waduk lainnya hubungannya dengan potensi pengembangan perikanan. Buletin Penelitian Perikanan Darat. 5 (1): 4755.

Umar, C. 1991. Distribusi plankton di Waduk Cirata, Jawa Barat pada tahun 19881989. Buletin Penelitian Perikanan Darat. 10 (1): 1-9. 